\title{
FACTORS AFFECTING CONTACT DERMATITIS ON PALM OIL PLANTATION WORKERS OF PT. $X$ IN SEMITAU SUB-DISTRICT
}

\author{
Agus Fitriangga ${ }^{1}$. Ambar Rialita ${ }^{2}$. and Adinda Rabiattun Adawiah ${ }^{3}$ \\ ${ }^{1}$ Department of Public Health, Faculty of Medicine, Universitas \\ ${ }^{2}$ Dermatologist, Faculty of Medicine, Universitas Tanjungpura \\ ${ }^{3}$ Tanjungpura Third-year medical student, Faculty of Medicine, Universitas Tanjungpura
}

Corresponding author: Agus Fitriangga

Email: afitriangga@medical.untan.ac.id

\begin{abstract}
The prevalence of occupational skin diseases reaches $20 \%$ up to $70 \%$ around the world. Occupational contact dermatitis cases reached 1.3-8.1 per 10,000 full-time workers per year in two decades. This research aims to identify the relationship between predisposing factors, enabling factors, and reinforcing factors on the contact dermatitis cases on palm oil plantation workers of PT. $X$ in Semitau Subdistrict. This study design was a cross-sectional involving 72 samples. The independent variables covered age, gender, level of knowledge, use of Personal Protective Equipment (PPE), tenure, chemical contact, personal hygiene, history of occupational dermatitis, occupational history, and Occupational Safety and Health Management System (SMK3). Then, the dependent variable was occupational dermatitis cases. A total of $54.2 \%$ of respondent suffered from occupational dermatitis. Some respondent were elderly (43.1\%) and most of the subject were female (62.5\%). The respondents had a good level of knowledge (37.5\%), good personal hygiene (52.8\%), and use complete PPE (25\%). A total of $51.4 \%$ of respondent did not have chemical contacts and those who have $<2$ years of tenure reached $45.8 \%$. Most of the subjects did not have an occupational history (81.9\%) and occupational dermatitis history (75\%). Half of the subjects had a good level of application of SMK3. Chi-Square Test results showed significant values of personal hygiene, use of PPE, and a history of the disease $(<0.05)$ with $p$ values of $<0.05$. There is a strong relationship between personal hygiene, the use of PPE, and the history of occupational dermatitis on palm oil plantation workers of PT. $X$ in Semitau Subdistrict.
\end{abstract}

Keywords: Contact Dermatitis, Palm Oil Plantation Workers, Predisposing Factor, Enabling Factor, Strengthening Factor.

\section{INTRODUCTION}

The prevalence of occupational contact dermatitis cases reaches 20 to $70 \%$ around the world. A journal entitled Occupational Dermatoses reported that the occupational contact dermatitis accounts for $1.3-8.1$ per 10,000 full-time workers per year in two decades $^{1,2}$.

Occupational contact dermatitis can be categorized into irritant and allergic contact dermatitis. Referring to the U.S. Bureau of Labor Statistics data, $80 \%$ out of 249,000 non-fatal occupational diseases in 2004 were irritant contact dermatitis ${ }^{3}$.

In Indonesia, occupational contact dermatitis reached $92.5 \%$, while skin infections and other skin diseases reached $5.4 \%$ and $2.1 \%$ respectively. ${ }^{2}$ In epidemiological studies, $97 \%$ of 389 cases are contact dermatitis covering irritant contact dermatitis $(66.3 \%)$ and allergic contact dermatitis $(33.7 \%)^{4}$.

Based on the data gained from Finland and the United States, farmers have the highest case of occupational contact dermatitis. ${ }^{5}$ A study in California found that active ingredients such as emulsifiers, surfactants, or biocides can cause DKI or DKA on farmers. ${ }^{6}$ Data gained from $X$ clinic in PT. $X$, showed a total of 167 contact dermatitis cases in August 2017 - 2018.

Palm oil plants become a promising source of nonoil and gas foreign exchange for Indonesia. PT. $X$ is a business group engaged in the largest palm oil plantation in West Kalimantan. The success of the palm oil industry is certainly related to the quality of the products, so it is necessary to consider seed varieties, soil types, water, and adequacy of nutrients. The process of fertilizing, spraying pesticides, harvesting, and treatment were done manually. These activities allow the exposure of chemicals either directly or indirectly, thus the workers have a higher possibility of skin diseases, for example, occupational contact dermatitis. Factors affecting occupational contact dermatitis have to be studied further to create more effective prevention which finally results in maintaining workers' productivity. Thus, the study identifies factors affecting occupational contact dermatitis on palm oil plantation workers of PT. $X$ in Semitau Subdistrict. 


\section{METHODS}

This study is observational analytic with a crosssectional research design. It was conducted in December 2018 in PT. X in Semitau Subdistrict, Kapuas Hulu District. The target population of the study was all palm oil plantation workers of PT. $X$ in Semitau Subdistrict, Kapuas Hulu District. The amount of samples was 72 subjects. They were selected based on non-probability consecutive sampling technique. The sample was counted using the Slovin formula. This study used primary data collected from questionnaires and observation sheets. The data were processed using Chi-square test of SPSS 21 in which its stages covered data editing, data coding, data entry, and data cleaning. The data analysis covered univariate and bivariate analysis. The data analysis covered univariate and bivariate analysis.

The study was conducted after passing the ethical review by the Research Ethics Committee of The Medical Education Study Program of The Faculty of Medicine, Tanjungpura University (UNTAN) with letter number 1745 / UN22.9 / DL / 2019.

\section{RESULTS}

\section{Univariate Analysis}

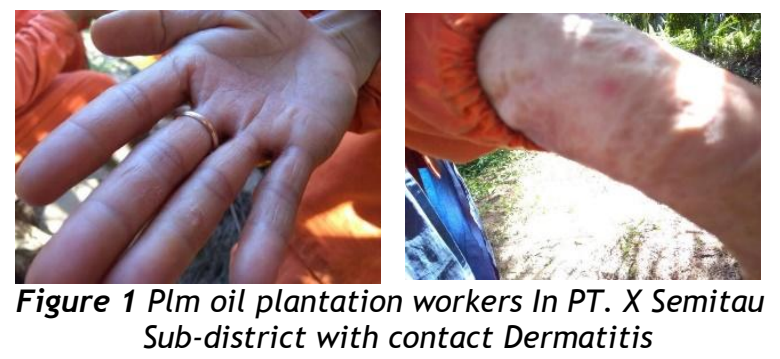

A total of 39 out of 72 subjects suffered from contact dermatitis (54.2\%). The respondents of the study was grouped based on the type of works such as fertilizing, spraying, maintenance, and harvesting. Based on this category, the result showed that the highest number of contact dermatitis case was found in maintenance worker with a total of 15 workers $(41.0 \%)$.

The predisposing factors above covered age, sex, level of knowledge, personal hygiene, chemical contact, tenure, and the use of PPE. The workers consisted of 41 young workers (56.9\%) and 31 old workers $(43.1 \%)$. The workers consisted of females $(66.7 \%)$ and males (33.3\%). Based on the level of knowledge, most of them have a poor level of knowledge $(62.5 \%)$ but 27 workers have a good level of knowledge (37.5\%). In terms of personal hygiene, 34 workers $(47.2 \%)$ have poor personal hygiene and the rest (38 workers) have good personal hygiene $(52.8 \%)$. A total of 54 workers used complete PPE (75\%) but the rest (25\%) did not. Then, 35 workers had chemical contact
(48.6\%) and the rest $(51.4 \%)$ did not. Based on tenure, $54.2 \%$ of the subjects have worked for $>2$ years and the rest $(45.8 \%)$ worked for less than 2 years. Table 1

Enabling factors consisted of occupational dermatitis history and occupational history. Regarding occupational history, 13 workers have it $(18.1 \%)$ and 59 workers do not have it $(81.9 \%)$. Then, in term of occupational dermatitis history, 18 workers have it $(25 \%)$ and 54 workers do not have it $(75 \%)$. Table 2

The reinforcing factor consisted of application of SMK3. Based on this factor, the result indicated that 36 workers have a poor application of SMK3 $(50 \%)$ and the rest have good application of SMK3 (50\%). Table 3.

\section{Bivariate Analysis}

Predisposing Factors

Based on the Chi-Square test, there was no relationship between the age variable $(P=0.207)$, chemical contact $(P=0.245)$, tenure $(P=0.571)$, sex $(P=0.400)$, and level of knowledge $(P=0.291)$ with contact dermatitis on palm oil plantation workers of PT. X. On the other hand, the personal hygiene variable $(P=0.008)$ and the use of PPE $(P$ $=0.038$ ) showed a relationship with the contact dermatitis on field workers of PT. X. Table 4

\section{Enabling Factor}

Based on the Chi-Square test, there was a relationship between the history of contact dermatitis $(P=0.019)$ with the contact dermatitis case on field workers of PT. $X$. On the other site, there was no significant relationship between occupational history $(P=0.392)$ with the contact dermatitis case on field workers of PT.X. Table 5

\section{Reinforcing Factors}

Based on the Chi-Square test, it gained $P$ values of $0.078(P>0.005)$. Thus, $H_{\circ}$ is rejected and there is no significant relationship between the application of SMK3 and contact dermatitis on field workers of PT. Table 6

\section{DISCUSSION}

\section{Predisposing Factors \\ Age}

Age can be a protective factor for skin. The younger age had the better skin fat layer and protection for the skin so that infectious agents will not easily attack ${ }^{7}$. The result of a study conducted in PT. $X$ is in line with the theory that that old workers were more susceptible to contact dermatitis compared to the younger workers. However, the statistical test showed that there is no relationship between age and contact dermatitis. It indicates that older people were more at risk, but they are wiser in working and have higher compliance to the standard procedures compared to younger workers. 
Table 1: Predisposing Factors of Contact Dermatitis

\begin{tabular}{|c|c|c|c|c|}
\hline No. & Variables & Category & Frequency & Percent (\%) \\
\hline \multirow{2}{*}{1.} & \multirow{2}{*}{ Age } & Young & 31 & 43.1 \\
\hline & & Old & 41 & 56.9 \\
\hline \multirow{2}{*}{2.} & \multirow{2}{*}{ Chemical contact } & Yes & 35 & 48.6 \\
\hline & & No & 37 & 51.4 \\
\hline \multirow{2}{*}{3.} & \multirow{2}{*}{ Tenure } & Risky & 39 & 54.2 \\
\hline & & Not risky & 33 & 45.8 \\
\hline \multirow{2}{*}{4.} & \multirow{2}{*}{ Sex } & Female & 48 & 66.7 \\
\hline & & Male & 24 & 33.3 \\
\hline \multirow{2}{*}{5.} & \multirow{2}{*}{ Level of knowledge } & Poor & 45 & 62.5 \\
\hline & & Good & 27 & 37.5 \\
\hline \multirow{2}{*}{6.} & \multirow{2}{*}{ Personal hygiene } & Poor & 34 & 47.2 \\
\hline & & Good & 38 & 52.8 \\
\hline \multirow{2}{*}{7.} & \multirow{2}{*}{ Use of PPE } & Complete & 54 & 75.0 \\
\hline & & Not complete & 18 & 25.0 \\
\hline
\end{tabular}

Table 2: Enabling Factors of Contact Dermatitis

\begin{tabular}{|c|c|c|c|c|}
\hline No. & Variables & Category & Frequency & Percent (\%) \\
\hline \multirow{2}{*}{1.} & \multirow{2}{*}{ Occupational dermatitis history } & Yes & 18 & 25.0 \\
\hline & & No & 54 & 75.0 \\
\hline \multirow{2}{*}{2.} & \multirow{2}{*}{ Occupational history } & Yes & 13 & 18.1 \\
\hline & & No & 59 & 81.9 \\
\hline
\end{tabular}

Table 3: Reinforcing Factor of Contact Dermatitis

\begin{tabular}{ccccc}
\hline No. & Variables & Category & Frequency & Percent (\%) \\
\hline \multirow{2}{*}{ 1. } & \multirow{2}{*}{ Application of SMK3 } & Poor & 36 & 50.0 \\
& & Good & 36 & 50.0 \\
\hline
\end{tabular}

Table 4. The Result of Bivariate Analysis of Predisposing Factors

\begin{tabular}{|c|c|c|c|c|c|c|c|c|c|c|}
\hline \multirow{2}{*}{ No. } & \multirow{2}{*}{ Variables } & \multirow{2}{*}{ Category } & \multicolumn{4}{|c|}{ Contact Dermatitis } & \multirow[t]{2}{*}{$\mathbf{N}$} & \multirow{2}{*}{$P$ value } & \multicolumn{2}{|c|}{$95 \% \mathrm{Cl}$} \\
\hline & & & Yes & $\%$ & No & $\%$ & & & Lower & Upper \\
\hline \multirow{2}{*}{1.} & \multirow{2}{*}{ Age } & Young & 20 & 48.8 & 21 & 51.2 & 41 & \multirow{2}{*}{0.207} & 0.21 & 0.57 \\
\hline & & Old & 19 & 61.3 & 12 & 38.7 & 31 & & 0.36 & 0.67 \\
\hline \multirow{2}{*}{2.} & Chemical & Yes & 17 & 48.6 & 18 & 51.4 & 35 & \multirow{2}{*}{0.254} & 0.34 & 0.69 \\
\hline & contact & No & 22 & 59.5 & 15 & 40.5 & 37 & & 0.24 & 0.57 \\
\hline \multirow{2}{*}{3.} & & Risky & 21 & 53.8 & 18 & 46.2 & 39 & \multirow{2}{*}{0.571} & 0.30 & 0.63 \\
\hline & Ienure & Not risky & 18 & 53.5 & 15 & 45.5 & 33 & & 0.28 & 0.63 \\
\hline \multirow{2}{*}{4.} & \multirow{2}{*}{ Sex } & Female & 26 & 57.8 & 19 & 42.3 & 45 & \multirow{2}{*}{0.400} & 0.29 & 0.58 \\
\hline & & Male & 12 & 50.0 & 12 & 50.0 & 27 & & 0.28 & 0.72 \\
\hline \multirow{2}{*}{5.} & Level of & Poor & 26 & 57.8 & 19 & 42.2 & 45 & \multirow{2}{*}{0.291} & 0.27 & 0.57 \\
\hline & knowledge & Good & 13 & 48.1 & 14 & 51,9 & 27 & & 0.32 & 0.72 \\
\hline \multirow{3}{*}{6.} & Personal & Poor & 24 & 70.6 & 10 & 29.4 & 34 & \multirow{3}{*}{0.008} & 0.13 & 0.46 \\
\hline & hygiene & Good & 15 & 39.5 & 23 & 60.5 & 38 & & 0.44 & 0.77 \\
\hline & & Complete & 33 & 61.1 & 21 & 38.9 & 54 & & 0.25 & 0.52 \\
\hline 7. & Use of PPE & Not complete & 6 & 33.3 & 12 & 66.7 & 18 & 0.038 & 0.43 & 0.91 \\
\hline
\end{tabular}

Table 5. The Result of Bivariate Analysis of Enabling Factors

\begin{tabular}{|c|c|c|c|c|c|c|c|c|c|c|}
\hline \multirow{2}{*}{ No. } & \multirow{2}{*}{ Variables } & \multirow{2}{*}{ Category } & \multicolumn{4}{|c|}{ Contact Dermatitis } & \multirow[t]{2}{*}{$\mathbf{N}$} & \multirow[t]{2}{*}{$P$ value } & \multicolumn{2}{|c|}{$95 \% \mathrm{Cl}$} \\
\hline & & & Yes & $\%$ & No & $\%$ & & & Lower & Upper \\
\hline \multirow[b]{2}{*}{1.} & \multirow{2}{*}{$\begin{array}{c}\text { Occupational } \\
\text { dermatitis history }\end{array}$} & Yes & 14 & 77.8 & 4 & 22.2 & 18 & \multirow{2}{*}{0.019} & 0.01 & 0.43 \\
\hline & & No & 25 & 46.3 & 24 & 53.7 & 54 & & 0.40 & 0.67 \\
\hline 2. & $\begin{array}{l}\text { Occupational } \\
\text { history }\end{array}$ & $\begin{array}{c}\text { Risky } \\
\text { Not risky }\end{array}$ & $\begin{array}{c}8 \\
31\end{array}$ & $\begin{array}{l}61.5 \\
52.5\end{array}$ & $\begin{array}{c}5 \\
28\end{array}$ & $\begin{array}{l}38.5 \\
47.5\end{array}$ & $\begin{array}{l}13 \\
59\end{array}$ & 0.392 & $\begin{array}{l}0.08 \\
0.34\end{array}$ & $\begin{array}{l}0.69 \\
0.61\end{array}$ \\
\hline
\end{tabular}


Table 6. The Result of Bivariate Analysis of Reinforcing Factors

\begin{tabular}{ccccccccccc}
\hline \multirow{2}{*}{ No. } & \multirow{2}{*}{ Variables } & \multirow{3}{*}{ Category } & \multicolumn{3}{c}{ Contact Dermatitis } & $\mathrm{N}$ & $\mathrm{P}$ value & \multicolumn{2}{c}{$95 \% \mathrm{Cl}$} \\
\cline { 3 - 11 } & & & Yes & $\%$ & No & $\%$ & & & lower & Upper \\
\hline \multirow{2}{*}{ 1. } & Application of & Poor & 23 & 63.9 & 13 & 36.1 & 36 & 0.078 & 0.21 & 0.53 \\
& SMK3 & Good & 16 & 44.4 & 20 & 55.6 & 36 & & 0.38 & 0.73 \\
\hline
\end{tabular}

\section{Chemical Contact}

The results of the analysis showed that there is no relationship between chemical contact and contact dermatitis on workers of PT. X concerning the company regulation of less than 8 hours a day of contact to chemical exposure. Based on the applied Occupational Exposure Limits (OELs), the average exposure limits is 8 hours per day $^{8}$.

The workers of PT. $X$ do not exceed the maximum limit that has been determined, thus the possibility of occupational contact disorder caused by chemical exposure of contact can be avoided.

\section{Tenure}

Workers with a long tenure are not at risk of contact dermatitis because their skin has been resistant to certain substance around the workplace. Conversely, workers with a short tenure have more sensitive skin and vulnerable to suffer from contact dermatitis 9

In this study, tenure does not have relationship with the contact dermatitis case. It might be due to other factors such as direct chemical contact and other factors. Referring to the theory, workers with a short tenure are more vulnerable to DKAK, but possibly those who have worked longer are less careful as they have more experiences and do not comply to the standard procedures.

\section{Sex}

Based on the Aesthetic Surgery Journal, women have fewer hair follicles, sweat glands and hormones, and thinner skin than men. Thus, they are more vulnerable to suffer from Occupational Dermatoses $^{10}$.

There is no relationship between sex with the contact dermatitis on workers of PT. $X$ due to unequal proportion of subjects. The contact dermatitis case is more common in women, but it can be influenced by the workplace, works, and

materials causing skin irritation. In addition, it is also affected by the use of personal protective equipment (PPE). Without using the PPE, it is possible for workers, both men and women, to suffer from contact dermatitis.

\section{Level of knowledge}

Lack of knowledge about contact dermatitis makes workers more susceptible to contact dermatitis. Knowledge will influence workers in working when using chemicals. For example, if workers do not wash their hands immediately after being exposed to chemicals, then the chemical can be absorbed by the skin ${ }^{11}$.

In this study, there was no relationship between the level of knowledge and the contact dermatitis. Even though the workers have a low level of knowledge (62.5\%), the company has set its standard procedure, but $75 \%$ of workers have used of incomplete PPE is incomplete. But, the most influential factors such as contact duration not exceed the maximum limit a day to reduce the risk of occupational contact dermatitis.

\section{Personal Hygiene}

Personal hygiene is an effort to prevent skin diseases. One of the personal hygiene efforts to prevent contact dermatitis is maintaining skin cleanliness. In this study, skin hygiene refers to workers' habit to maintain their skin before and after work covering bathing, using soap, using clean towels and clothes. Therefore, personal hygiene plays an important role ${ }^{12}$.

The field workers of PT. $X$ do not have a good level of awareness to maintain their personal hygiene. Washing hand after working or chemical exposure can reduce the potential cause of dermatitis.

PT. $X$ has not provided sufficient washing hand facilities around the plantation area. The facilities were only available at the Occupational Safety and Health Management System (SMK3) office which is far from the plantation area. Before starting working, some workers have washed their hands and even took a bath. After working, they only wash their hands with trench water around the plantation area. Then, they dried their hands using their clothes. They took a bath after returning to their homes. It indicates that level of awareness of maintaining personal hygiene before, during, and after work is still low. Based on the results of interviews with workers, most of them do not know how to wash their hands properly which includes 7 steps. They also do not routinely replace or wash their gloves, take a shower immediately after work, clean toiletries, and use clean clothes before starting work. Thus, the chemical stain is not washed properly and it might increase the risk of contact dermatitis.

\section{The Use of PPE}

The use of PPE is one of ways to prevent occupational contact dermatitis as it will protect workers from direct chemical expossure ${ }^{13}$. The 
workers of PT. $X$ in apply fertilizers and pesticides to the palm oil trees. During the process, they have to use PPE including vinyl gloves, boots, masks, and helmets. However, not all workers are accustomed to using the PPE completely and in accordance with applicable Occupational Safety and Health Management System (SMK3) during working. It is because they assume that the use of PPE makes them feel discomfort and limit their movement.

Inappropriate selection of gloves can also affect chemical contamination at work. During the study, the researchers found that the workers have used gloves, but they still suffer from contact dermatitis after applying the fertilizer. It is likely possible because their gloves are made of knitted cotton which still allow chemicals contact. However, the company has provided vinyl gloves which are better to protect their skin from direct chemical exposure.

\section{Enabling Factor}

\section{History of Contact Dermatitis}

Skin diseases can be caused by several factors such as working environment and daily habits. The current skin disease case can be caused by the history of previous skin disease. It is triggered by exposure to chemicals at work such as fertilizers and pesticides. A healthy and clean environment will have a good effect on the skin and vice versa. Thus, it is crucial to consider working environment. The history of previous dermatitis contact can be one of the factors that caused the current contact dermatitis (repeated history). Excessive reaction to certain substance will trigger the previous skin disease to occur ${ }^{14}$.

The workers' awareness on the living condition is still low. This can be seen from the level of personal hygiene of most workers which is considered poor. It becomes an indication of the level of cleanliness of the living and working environment. This condition can trigger repeated contact dermatitis on workers with skin disease history.

\section{Occupational History}

A total of 13 out of 72 workers have occupational history with $61.5 \%$ of them suffering from contact dermatitis. There is no relationship between the types of work with the contact dermatitis on palm oil workers. It is because most workers have never had a job which is susceptible to contact dermatitis. Based on the results of interviews, female workers were previously work as housewives and male workers are fresh graduates of junior high school and unemployed. Most of workers with occupational history previously work in rubber plantation.

Latex workers processed latex using hands and feet in latex pool which its coagulation process is not perfect. They do not use any protection. The process took several hours and it required them to work in a wet and exposed to chemicals. Thus, they can suffer from contact dermatitis. ${ }^{15}$

\section{Reinforcing Factor}

\section{Application of SMK3}

The responsibility triangle shows that the company and each employee have to be fully aware that occupational safety and health is a shared responsibility. It provides an answer to the study in which there is no statistical relationship because it only measures the application of SMK3 for employees, not for the company.

Thus, to measure the effect of the SMK3 on occupational contact dermatitis, it needs to involve the company. The application of SMK3 will not have a significant impact for the prevention if it is not followed by company's compliances to the applicable SMK3 ${ }^{16}$.

\section{CONCLUSION}

There is a relationship between personal hygiene, the use of PPE, and history of previous skin diseases with the contact dermatitis on palm oil plantation workers of PT. $X$ in Semitau Subdistrict. The authors declare no potential conflict of interest.

\section{REFERENCES}

1. Lisa Kostner et al. Allergic contact dermatitis. Department of dermatology. University hospital zurich. Immunol allergy clin $\mathrm{n}$ am 2017; 37: 141-152.

2. Indonesian Skin And Genital Specialist Association. Jakarta: category health gallery, contact dermatitis. 2009.

3. Hogan, D.J. Contact dermatitis allergic'. eMedicine Dermatology. http://emedicine.medscape.com/art icle/1049216-overview. (Accesed 3 April 2010).

4. Hudoyono, J. Occupational Dermatosis. Indonesian Medical Magazines. 2002.

5. Meyer JD, Chen Y, Holt DL, Beck MH, Cherry NM. Occupational contact dermatitis in the UK: a surveillance report from EPIDERM and OPRA. Occupational Medicine 2000; 50: 26573.

6. Marks JG, Elsner P, Deleo VA. Contact and occupational dermatology. Mosby 2002: 10-343. 
7. Utami MF. Analysis of risk factors related to the incidence of irritant contact dermatitis in nurse rsup dr. Moh. Hoesin palembang in the year 2014 . Journal Sriwijaya University 2015.

8. Rachmasari N. Factors related to incidence of irritant contact dermatitis on metal craftsmen in cepogo village, cepogo subdistrict of boyolali district. Journal of Public Health (E-Journal) 2013 ; 2 (1).

9. Putri F Y, Suwondo A, Widjasena B. Exposure of wood dust with the incidence of irritant contact dermatitis on furniture worker PT. X jepara. Journals of Public Health (EJournal) 2016; 4 (4):652-658.

10. Anshar R, Pramuningtyas R, Usdiana D. Wet worker relationship with incidence of contact dermatitis due to medical personnel in hospital $\mathrm{x}$ tanjung. Biomedika 2016 ; (2):2530.

11. Prakoso, N R. Factors related to incidence of irritant contact dermatitis on steam workers of motor vehicles in ciputat east district. Syarid Hidayatullah State Islamic University Jakarta 2017.

12. Rahma G A, Setyaningsih $Y$, Jayanti $S$ Analysis of exogenous and endogenous factors on the incidence of occupational dermatitis in skin tanning workers PT. Adi satria abadi piyungan, bantul. Journals of Public
Health (E-Journal) 2017 ; 5 (5): 173182.

13. Putri S A, Nirmala F, Akifah. Factors related to the symptoms of contact Dermatitis on Motor workshop workers in the city of Kendari in the year 2016. Jimkesmas(Scientific Journal of Public Health) 2017; 2 (6).

14. Ahyanti M, Purwono P. Risk of skin diseases caused by working in rubber plantation and processing company. Medical Polytechnic Health Journal, Ministry of Tanjung Karang 2019; 10 (1): 1-8.

15. Suryani, Norma D., Martini., Susanto ,Henry, Setyawan. Comparative risk factors for the incidence of irritant contact dermatitis between salt farmers and rice paddy farmers in kaliori district rembang. Journals of Public Health (E-Journal) 2017;5 (4): 444-455.

16. Pertiwi P. Relationship between occupational safety and health (k3) with occupational accident incident at PT.Assorted adhilogam karya ceper klaten. Muhammadiyah Surakarta University 2016. 